Bull. Mater. Sci., Vol. 23, No. 4, August 2000, pp. 263-266. (C) Indian Academy of Sciences.

\title{
Incorporation of cobalt and nickel metal nano-particles in nano-grain zirconia film matrix by solution route
}

\author{
S JANA ${ }^{\dagger}$ and P K BISWAS* \\ Sol-Gel Division, ${ }^{\dagger}$ Glass-Ceramic Coating Division, Central Glass and Ceramic Research Institute, Calcutta 700032 , India
}

\begin{abstract}
Precursor solutions of cobalt/nickel incorporated nano-grain zirconia films were prepared from aquo-organic solutions of zirconium oxychloride octahydrate and corresponding transition metal nitrate. The films were deposited onto silica glass substrate by the dipping technique. Annealing was made at different temperatures from $450^{\circ} \mathrm{C}$ to $1200^{\circ} \mathrm{C} \pm 5^{\circ} \mathrm{C}$ in air atmosphere. The range of thickness of the films baked at $4500^{\circ} \mathrm{C}$ was 1800-1870 $\AA$. For cobalt system $\mathrm{Co}_{3} \mathrm{O}_{4}$ was formed initially at $450^{\circ} \mathrm{C}$ which gradually transformed to alpha cobalt and next to cubic cobalt along with a non-stoichiometric compound $\left(\mathrm{Zr}_{0 \cdot 71} \mathrm{Co}_{0 \cdot 23} \mathrm{O}_{0 \cdot 06}\right)$ with increasing annealing temperature. On the other hand, for nickel system nickel metal of nano-size was observed in the nano-grain zirconia film matrix at $450^{\circ} \mathrm{C}$. By increasing annealing temperature to $1200^{\circ} \mathrm{C}$, a compound, $\mathrm{ZrNi}_{4} \mathrm{O}$, was formed which was found to be stable for $\sim 30$ days.
\end{abstract}

Keywords. Nano-grain zirconia; nano particles of cobalt and nickel metals; sol-gel.

\section{Introduction}

The metal elements of the first transition series have partially filled 3d-orbital either in the ground state of the free atom (all except $\mathrm{Cu}$ ) or in one or more of their chemically important ions (all except Sc) and these exhibit variable valencies in their oxides, complexes and also in some rare cases in free ions (Bogus and Kevan 1989). It is known that the metal oxides and/or the lower valent metal ions or metals either in pure state or incorporated in a suitable matrix have implications for their applications as promising catalysts (Ghosh and Kevan 1990), nonlinear optical materials (Ando et al 1995) and optical filters (Ulrich 1988). Moreover, there are wide applications of $\mathrm{M}(\mathrm{Co} / \mathrm{Ni} / \mathrm{Cu}) /$ zirconia or yttria stabilized zirconia cermets traditionally used as anodes in the solid oxide fuel cell configuration (Echigoya et al 1996; Sammes et al 1996). Zeng et al (1995) and Zeng and Shi (1995) have studied nickel impregnated zirconia system by the sol-gel technique in detail which involved different valence states of nickel although the valence state of the starting nickel metal ion was 2.

The generation of lower valent oxides and/or ions/or generation of metals is usually done by hydrogen reduction (Ghosh and Kevan 1990), or by the irradiation (Bogus and Kevan 1989) of higher valence states. It has already been established that zirconium oxychloride octahydrate derived nano-grain zirconia film possesses oxygen deficiency in the zirconia network (Jana and Biswas

\footnotetext{
*Author for correspondence

"Paper presented at the 5th IUMRS ICA98, October 1998, Bangalore.
}

1997). Such oxygen deficient centres are so active that these can trap electrons (Liu et al 1995). If divalent transition metal ion be incorporated into the precursor solution of zirconia film, then it may be expected that the trapped electrons in the developed zirconia film matrix may reduce the transition metal ion. And in this case some special properties may be developed in the film.

Moreover the oxygen deficient zirconia may yield (Jana and Biswas 1997) partially stable $\mathrm{ZrO}_{2}-\mathrm{Zr}_{2} \mathrm{O}_{3}$ similar to the partially stabilized zirconia (Hillert 1991). Hence, both the phenomena, oxygen deficiency and partial stabilization of zirconia may yield $\mathrm{Co} / \mathrm{Ni} / \mathrm{Cu}$ cermets in thin film form in relatively easy way. Hence, in this work only $\mathrm{Co}$ and $\mathrm{Ni}$ have been considered for the study of the metal incorporated zirconia films.

\section{Experimental}

\subsection{Preparation of precursor solutions}

The precursor solutions were prepared by using requisite amount of hydrated zirconium salt (e.g. zirconium oxychloride octahydrate), transition metal salts (e.g. cobalt nitrate hexahydrate), organic solvents (e.g. ethanol, 2butanol) and complexing or polymeric agent (e.g. glacial acetic acid). The atomic ratio of $\mathrm{Zr}: \mathrm{M}(\mathrm{M}, \mathrm{Co} / \mathrm{Ni})$ in the solutions was $1: 1$. Two solutions (types I and II corresponding to zirconium and transition metal salts) were initially prepared separately by dissolution in suitable solvents and addition of a complexing agent if necessary and next, these two solutions were mixed and stirred with a magnetic paddle for about $30 \mathrm{~min}$. These solutions were aged for $120 \mathrm{~h}$ and used as precursors of the films. The 
flow chart (figure 1) displays a pictorial view of preparation of precursor solutions.

\subsection{Deposition of films}

The films were deposited on cleaned (Atta et al 1990) pure silica glass substrate using the above aged precursor sols/solutions. These were done by the dipping technique with a withdrawal speed of $18 \mathrm{~cm} / \mathrm{min}$. A solution layer was formed on both sides of the glass substrate. Freshly

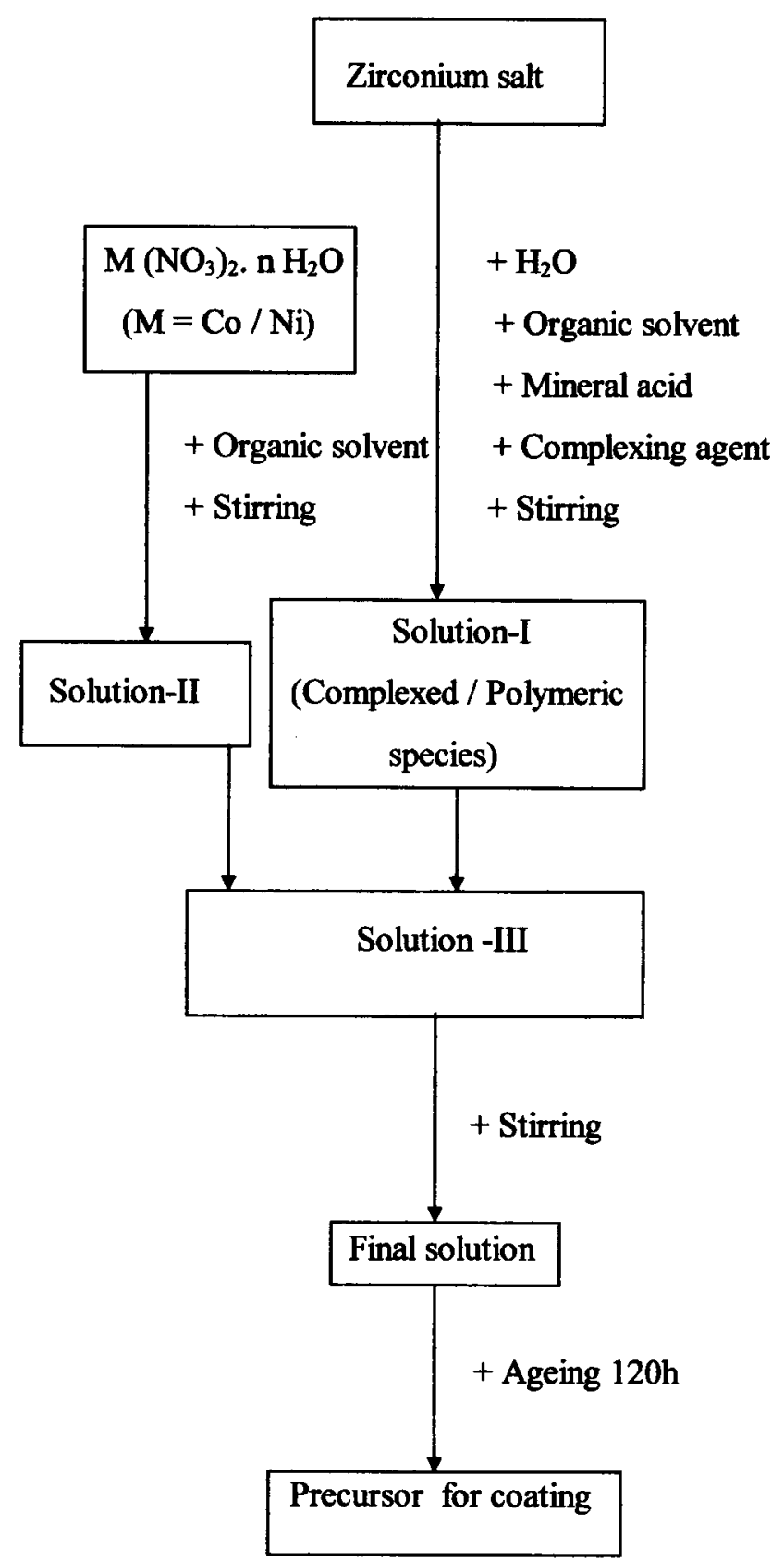

Figure 1. Flow chart of preparation of precursor for film formation. prepared solutions resulted in patch-like (inhomogeneous) films but after ageing for $\sim 120 \mathrm{~h}$, homogeneous films were developed. After dipping, the coated samples were placed in an air oven and heated at $100^{\circ} \mathrm{C}$ for $30 \mathrm{~min}$ and then put into a furnace for baking at $450^{\circ} \pm 5^{\circ} \mathrm{C}$ in air atmosphere when oxide films were usually generated. Next these were annealed at different selected higher temperatures $\left(600^{\circ}, 730^{\circ}, 940^{\circ}\right.$ and $\left.1200^{\circ} \pm 5^{\circ} \mathrm{C}\right)$ in the same atmosphere. The duration of annealing was $30 \mathrm{~min}$ in each case.

\subsection{Characterization of films}

Absorption spectra of the films were recorded by using Shimadzu UV-VIS-NIR spectrophotometer (model, UV3101PC) and paramagnetic properties of the films were measured at room temperature by utilizing a JEOL, JESRE1 spectrometer operating in the X-band condition with $100 \mathrm{kHz}$ field modulation. DPPH standard marker was used to calibrate ESR parameters. Crystallinity of the films were checked by a X-ray diffraction unit (Philips PW 1730) employed with nickel filter $\mathrm{CuK}_{\alpha}$ radiation. A JEOL, JEM-200CX, transmission electron microscope (TEM) was employed to analyse the microstructure of the films. The thickness of the films was measured by stylus method (Sloan, DEKTAK).

\section{Results and discussion}

Cobalt nitrate incorporated zirconia precursor sol/solution layer deposited on silica glass substrate transforms to gel on air drying. When it is heated to around $450^{\circ} \mathrm{C}$ in an electrical furnace most of the organics are evaporated off and/or decomposed to generate oxide film. In this case, it is expected from literature (Mellor 1935) that at around $300^{\circ} \mathrm{C}$ formation of $\mathrm{Co}_{3} \mathrm{O}_{4}$ started and at $450^{\circ} \mathrm{C}$ considerable amount of $\mathrm{Co}_{3} \mathrm{O}_{4}$ was formed as evident from the

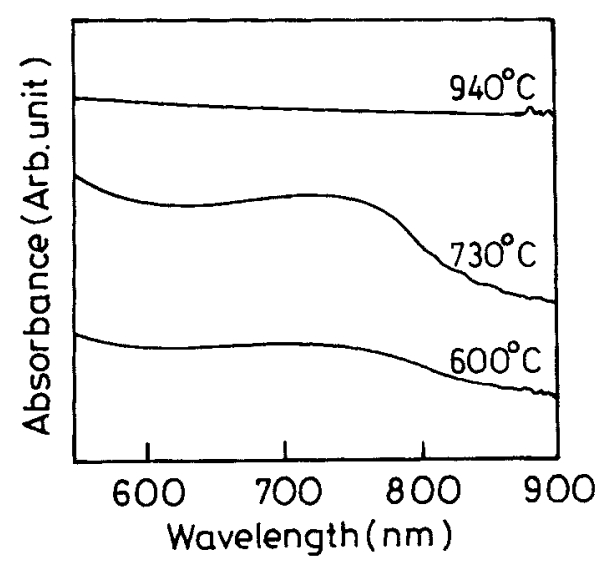

Figure 2. Absorption spectra of cobalt incorporated nanograin zirconia films in the visible region. 
appearance of characteristic absorption band $(\sim 730 \mathrm{~nm})$ (Ando et al 1995) in the visible spectra of the film which became prominent (figure 2) for the sample annealed at $730^{\circ} \mathrm{C}$. It was observed from $\mathrm{X}$-ray diffractograms (figure 3 ) of the samples annealed at different higher temperatures, viz. $600^{\circ}, 730^{\circ}$ and $940^{\circ}$, that a mixture of $\alpha$-cobalt $\left(2 \theta=37^{\circ}\right)$ and cubic spinel $\mathrm{Co}_{3} \mathrm{O}_{4}\left(2 \theta=37^{\circ}\right)$ phases were possibly formed at $730^{\circ} \mathrm{C}$. The $\alpha$-cobalt transformed to cubic form of cobalt at $940^{\circ} \mathrm{C}$. It is also interesting to note that a non-stoichiometric compound, $\mathrm{Zr}_{0 \cdot 71} \mathrm{Co}_{0.23} \mathrm{O}_{0.06}$, was also formed $\left(2 \theta=38^{\circ}\right.$, strong and $65^{\circ}$, weak) at this high temperature $\left(1200^{\circ} \mathrm{C}\right)$. This probably happened during the transformation of alpha-cobalt to cubic cobalt when the liberated cobalt metal possibly reacted with the host material, zirconia. As the cobalt metal itself is a reducing agent, it reduced zirconia which instantaneously reacted with some of the residual cobalt metal and formed the above nonstoichiometric compound. The TEM picture (figure $4 \mathrm{a}$ ) of a typical sample, annealed at $730^{\circ} \mathrm{C}$ shows the clusters of cobalt metal which disappeared (not shown here) at $1200^{\circ} \mathrm{C}$ possibly due to evaporation of cobalt metal.

On baking the nickel incorporated zirconia sol/solution layer deposited on silica glass it was observed that in the

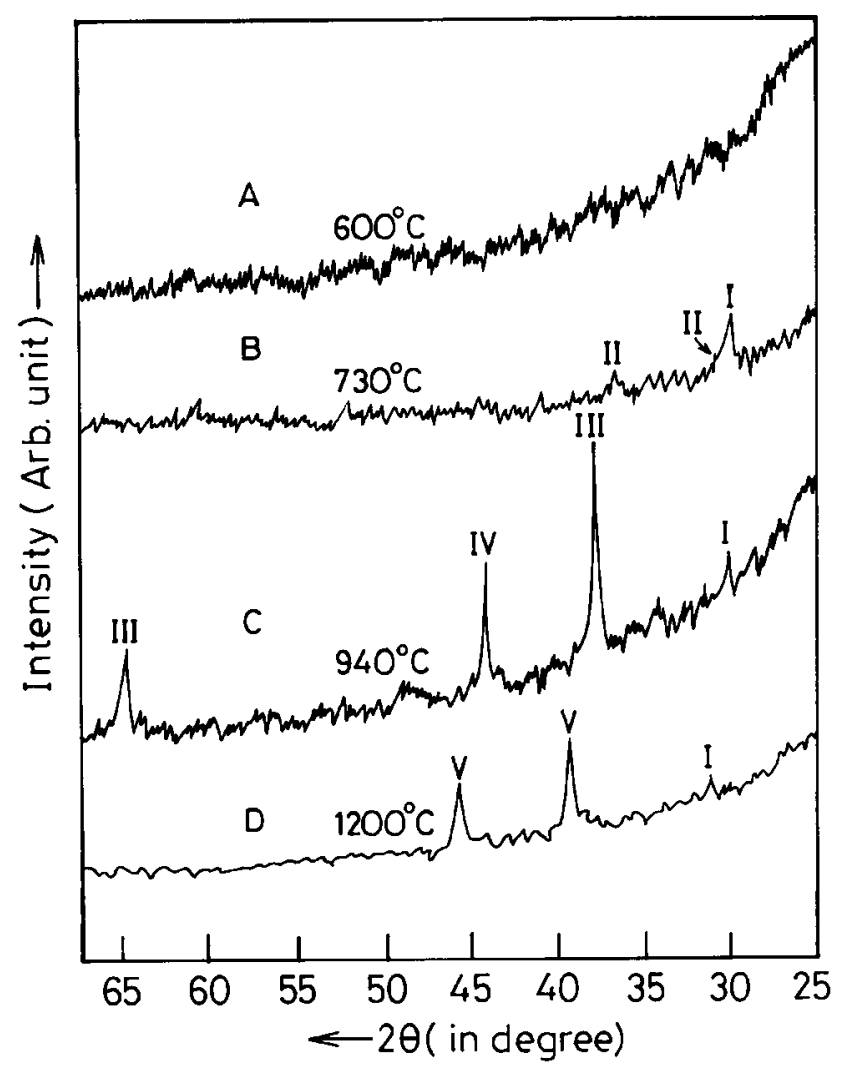

Figure 3. X-ray diffractograms of the samples prepared by annealing the cobalt $\left(\mathrm{A}, 600^{\circ} \mathrm{C} ; \mathrm{B}, 730^{\circ} \mathrm{C}\right.$ and $\left.\mathrm{C}, 940^{\circ} \mathrm{C}\right)$ and nickel $\left(\mathrm{D}, 1200^{\circ} \mathrm{C}\right)$ incorporated zirconia films (I, II, III, IV and $\mathrm{V}$ represent the characteristic $2 \theta$ peaks of the species, $t / c$ zirconia, $\alpha$-cobalt and/or cubic spinel $\mathrm{Co}_{3} \mathrm{O}_{4}, \mathrm{Zr}_{0 \cdot 71} \mathrm{Co}_{0.23} \mathrm{O}_{0.06}$ cubic cobalt metal and $\mathrm{ZrNi}_{4} \mathrm{O}$ respectively).

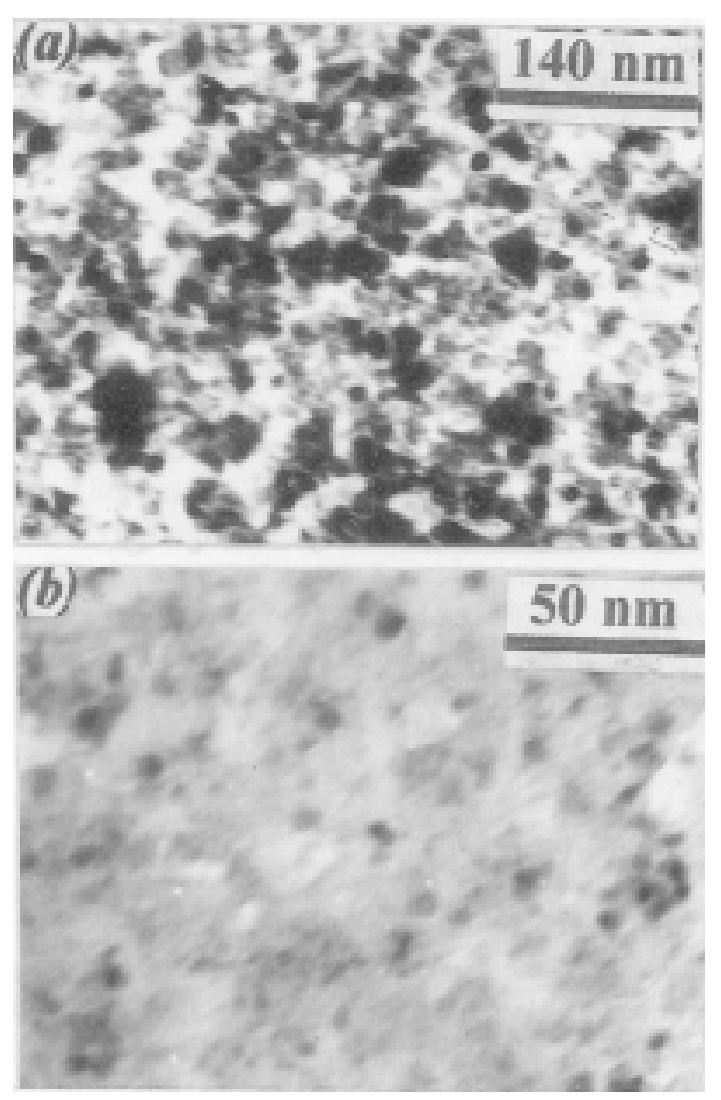

Figure 4. TEM micrographs of cobalt incorporated (a) annealed at $730^{\circ} \mathrm{C}$ and nickel incorporated (b) annealed at $450^{\circ} \mathrm{C}$ nanograin zirconia films.

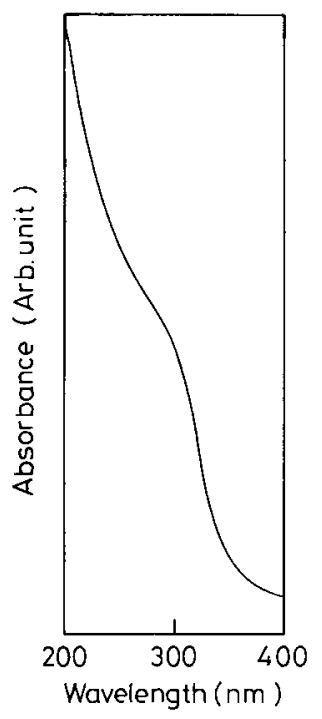

(a)

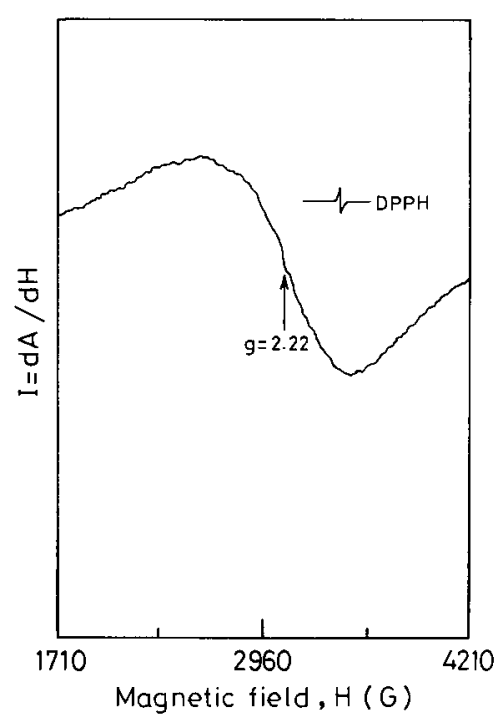

(b)
Figure 5. Ultraviolet spectrum (a) and ESR spectrum (b) of $450^{\circ} \mathrm{C}$ annealed nickel incorporated nano-grain zirconia films. 
developed oxide film the $\mathrm{Ni}$ (II) was partially reduced to metallic nickel as evidenced from the surface plasmon resonance (SPR) of $\mathrm{Ni}(0)$ (metallic nickel) at $\sim 3.6 \mathrm{eV}$ (Isobe et al 1995) in the ultraviolet spectrum (figure 5a) of the $450^{\circ} \mathrm{C}$ annealed sample. The ESR spectrum (figure $5 b)$ of the same sample showed a broad resonance signal with $g=2.23$ and peak to peak field $\sim 800 \mathrm{G}$ which might be attributed to $\mathrm{Ni}(0)$ (Bonneviot et al 1987; Bogus and Kevan 1989). Its formation might also be due to reduction of $\mathrm{Ni}(\mathrm{II})$ occurred by the trapped electrons present in the oxygen deficient centres of nano-grain zirconia (Jana and Biswas 1997). In addition a compound, $\mathrm{ZrNi}_{4} \mathrm{O}$ was also found to form in the case of $1200^{\circ} \mathrm{C}$ annealed sample as evident from its X-ray diffractogram (figure 3 ). The possible reason for formation of this species may be similar as described in the case of cobalt system. The TEM picture (figure $4 \mathrm{~b}$ ) of this film showed dark particles which might be due to $\mathrm{Ni}(0)$ and/or oxides of nickel.

\section{Conclusion}

This work reveals that starting with Co and Ni metal salts, corresponding metal may be incorporated in a suitable oxide matrix like zirconia if the grain/particle size of the host material be in the nano-size range. Although the content of metal was not quantified in this work but the knowledge of this would enlighten the future prospects on synthesis of metal cermets which are essential for SOFC devices.

\section{Acknowledgements}

The Director, CGCRI, Calcutta, is thankfully acknowledged for providing financial assistance to one of the authors (SJ) for his thesis work. Dr D Ganguli, Head, SolGel Division, is also duly acknowledged for his constant support and encouragement.

\section{References}

Ando M, Kadano K, Haruta M, Sakaguchi T and Miya M 1995 Nature 374625

Atta A K, Biswas P K and Ganguli D 1990 J. Non-Cryst. Solids 125202

Bogus W and Kevan L 1989 J. Phys. Chem. 933223

Bonneviot L, Cai F X, Che M, Kermarec M, Legendre O, Lepetit C and Olivier D 1987 J. Phys. Chem. 915912

Echigoya J, Hayashi S and Aoyagi E 1996 Mater. Sci. Forum 207-209 717

Ghosh A K and Kevan L 1990 J. Phys. Chem. 943117

Hillert M 1991 J. Am. Ceram. Soc. 742005

Isobe T, Park S Y, Weeks R A and Zuhr R A 1995 J. NonCryst. Solids 189173

Jana S and Biswas P K 1997 Mater. Letts 3053

Liu H, Feng L, Zhang X and Xue Q 1995 J. Phys. Chem. 99332

Mellor J W 1935 A comprehensive treatise on inorganic chemistry (London: Longmans)

Sammes N M, Brown M and Brown I W M 1996 J. Mater. Sci. 316069

Ulrich D R 1988 J. Non-Cryst. Solids 100174

Zeng H C and Shi S 1995 J. Non-Cryst. Solids 18531

Zeng H C, Lin J, Teo W K, Loh F C and Tan K L 1995 J. NonCryst. Solids 18149 